\title{
Gender Differences in Response to Experimental Pain among Medical Students from a Western State of India
}

Pratik Akhani,' Samir Mendpara, ${ }^{2}$ Bhupendra Palan, ${ }^{1}$ Jaman Harsoda. ${ }^{7}$

\begin{abstract}
Background: Pain is one of the most common reasons for patients to seek medical attention and it causes considerable human suffering. Pain is a complex perception that differs enormously among individual patients. Gender plays an important role in how pain is experienced, coped with and treated. Even young healthy individuals often differ in how they perceive and cope with pain. This study was done to investigate gender differences in response to experimental pain among medical students from a western state in India. Methods: A total of 150 medical students (86 males and 64 females) participated in this interventional study. The Cold Pressor Test was used to exert experimental pain. To study the response, cardiovascular measures (radial pulse, systolic blood pressure and diastolic blood pressure) and pain sensitivity parameters (pain threshold, pain tolerance and pain rating) were assessed. Results: No significant difference was found in cardiovascular response to experimental pain between both the genders ( $p>0.05)$. Pain threshold and pain tolerance were found to be significantly higher in males whereas pain rating was found to be significantly higher in females $(p<0.01)$. Pulse reactivity showed a negative relationship with pain threshold and pain tolerance whereas a positive relationship with pain rating, however no statistically significant relation was found between these measures. Conclusion: Females display greater pain sensitivity than males. Different pain perception might account for gender difference in pulse reactivity.
\end{abstract}

Keywords: Sex, Pain, Pain threshold, Pulse, Blood pressure (Source: MeSH-NLM).

\section{Introduction}

About the author: Dr. Pratik N. Akhani is Currently second year post graduate student of SBKS medical college, vadodara, India of a three-years program in their medical school.
Pain is the most common complaint that significantly contributes to patient suffering. Pain is an unpleasant feeling often caused by an intense or damaging stimuli, such as stubbing a toe, burning a finger, or putting alcohol on a cut. The International Association for the Study of Pain's widely used definition states: "Pain is an unpleasant sensory and emotional experience associated with actual or potential tissue damage, or described in terms of such damage". Pain is a complex neuro-physiological and psychological process that differs enormously among individual patients, even those who have similar injuries or illnesses.

Gender plays an important role in how pain is experienced, coped with and treated. ${ }^{2}$ Even young males and females often differ in how they perceive and cope with pain. ${ }^{3}$ In recent years gender differences in response to pain have received increased attention and multiple studies have investigated these differences using a wide variety of noxious stimuli. ${ }^{4} \mathrm{~A}$ number of studies have demonstrated a higher prevalence of chronic pain states and greater pain sensitivity among females compared with males. ${ }^{5}$ The expansive body of literature in this area suggests that females have lower pain thresholds and tolerance to a range of pain stimuli when compared to males. Additiona-
Ily, females generally report experiencing more recurrent pain, more severe pain and longer lasting pain than males. ${ }^{6}$ Many of the observed gender differences in pain prevalence (i.e., headache, abdominal and visceral pain) appear to reduce beyond the reproductive years. ${ }^{6}$ Males and females respond differently to various classes of pain medications, suggesting that physical pain relieving systems may differ in the two genders.? There is a growing body of literature that indicates females are more likely than males to be undertreated for their pain. It appears that gender affects not only pain perception, pain coping, and pain reporting, but also pain-related behaviors, including use of healthcare and the social welfare system. ${ }^{8}$

Gender differences in pain perception can vary across different cultures. ${ }^{6}$ There are not many studies regarding gender differences in pain perception from healthy individuals in India. We sought to illuminate whether gender differences exist in response to experimental noxious stimulus in young healthy medical students from a western state of India.

\section{Methods}

Prior approval for this study was obtained from Sumandeep Vidyapeeth Institutional Ethics Committee (SVIEC). It was an interventional study design with the cold pressor test being

Submission: Nov. 30, 2013

Acceptance: Jan. 27, 2014

Process: Peer-reviewed

\footnotetext{
${ }^{1}$ Department of Physiology, S. B. K. S. Medical Institute \& Research Center, Sumandeep Vidyapeeth, Piparia-391760, Vadodara, Gujarat, India.
}

${ }^{2}$ Department of Physiology, C. U. Shah Medical College, Surendranagar-363001, Gujarat, India.

Address: S. B. K. S. Medical Institute \& Research Center, Sumandeep Vidyapeeth, Piparia-391760, Vadodara, Gujarat, India. Email: pratikakhani@yahoo.com. 
the intervention. Data collection occurred before and after the cold pressor test. The study was conducted in the clinical laboratory, department of Physiology, S.B.K.S. medical institute and research centre. A total of 150 medical students ( 86 males and 64 females) from the S.B.K.S. medical institute and research centre participated as subjects. Written informed consent was obtained according to the ethical committee policy. Before testing, a detailed history was taken, followed by a general and systemic examination of subjects.

Young healthy students between 17-20 years of age, who were willing to give informed consent for participation, right handed (for selection of uniform study population, as handedness may affect sensitivity to pain. ${ }^{9}$ ), and females who were in pre-ovulatory phase of menstrual cycle (for selection of uniform study population, as pain perception may vary during different phases of menstrual cycle. ${ }^{10}$ ) were included in the study.

Students with a history of local/bone injury in the right hand (as this hand will be immersed in cold water), who were on any form of diet or exercise regime for weight loss or gain, who were taking any analgesics (as analgesics will reduce pain perception), and who were taking medications which may affect the Autonomic Nervous System were excluded. Students suffering from any known illness affecting or involving the Autonomic Nervous System e.g. Diabetes Mellitus, Thyroid disorder, any cardiovascular or neuropsychiatric disorder, any menstrual irregularities or disorders were also excluded from the study.

As showed in the CONSORT (Consolidated Standards of Reporting Trials) diagram," out of a total of 186 students who were approached for study, 150 were selected for study according to the inclusion and exclusion criteria (Figure 1).

The height was recorded during inspiration using a stadiometer. The subject was asked to stand erect on the stadiometer bare foot. The horizontal bar of the stadiometer was placed on the vertex of the subject and the readings were recorded.
Body mass was measured by a digital standing scale. The subject was asked to stand erect on the digital weighing machine bare foot and wearing light clothes. The readings were recorded from the digital scale of the weighing machine.

Body Mass Index measurement: The Body Mass Index (BMI) was calculated using the following formula:

Body mass index $(\mathrm{BMI})=$ Weight $($ in $\mathrm{kg}) /$ Height $^{2}\left(\text { in }^{2}{ }^{2}\right)^{12}$

For the Cold Pressor Test (experimental noxious thermal stimulus) subjects were asked to sit comfortably in a chair. After 10 minutes rest, the radial pulse, systolic blood pressure and diastolic blood pressure were recorded. A Laboratory water bath was filled with ice cold water, the temperature of which was maintained between $4^{\circ} \mathrm{C}$ and $8^{\circ} \mathrm{C}$ thorough the test using a laboratory thermometer. ${ }^{13}$ After that, the subject was asked to immerse his or her right hand into the laboratory water bath (palm down, water up to $5 \mathrm{~cm}$ above wrist level). Immediately, two stop watches were started. Subject was asked to determine intensity of pain during test and rate it on a scale of o to 10, Zero being no pain at all while 10 being the worst imaginable pain. ${ }^{14}$ When the subject felt pain for the first time, one stop watch was stopped. This time was taken as pain threshold (first feeling of pain). Once the pain was unbearable, the participant removed his or her hand and the second stop watch was stopped. This time was taken as pain tolerance. Immediately after the test, the radial pulse, systolic blood pressure and diastolic blood pressure were recorded. Blood pressures were recorded using a standardized mercury sphygmomanometer. All the measurements were done by a trained laboratory technician.

All the instruments were calibrated regularly using standard procedure as indicated.

Statistical analysis was done using SPSS version $17 ®$. Unpaired students t-test and Pearson's correlation were applied, $\mathrm{p}$-values $<0.05$ were considered significant.

Figure 1. CONSORT diagram showing selection of participants for study.

Approached for participation $(n=186)$

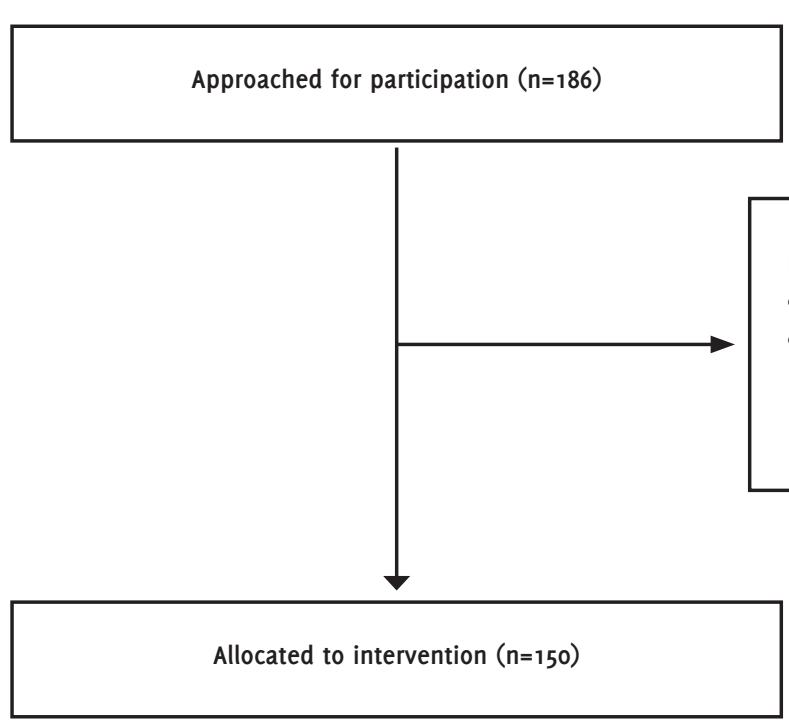

Excluded $(n=36)$

- Declined to participate $(n=17)$

- Not meeting inclusion criteria $(n=19)$

Left handed $(n=6)$

Not in pre-ovulatory phase $(n=13)$ 


\section{Results}

The study population included 86 male students and 64 female students (Table 1). The mean age of male students was 18.57 years and of female students was 18.37 years $(p=0.33)$. The mean height of male students was 1.57 meters and of female students was 1.58 meters $(p=0.43)$. The mean body mass of male students was $53.42 \mathrm{Kg}$ and of female students was 52.65 $\mathrm{Kg}(\mathrm{p}=0.50)$. The mean Body Mass Index of male students was $21.79 \mathrm{~kg} / \mathrm{m}^{2}$ and of female students was $21.14 \mathrm{Kg} / \mathrm{m}^{2}(p=0.11)$. Thus, the anthropometric parameters of both the study groups were fairly uniform with $p>0.05$ for all the parameters. were found to be significantly higher in males, whereas pain rating was found to be significantly higher in females. Thus females displayed greater pain sensitivity than males, a finding similar to Fillingim et $a l,{ }^{15}$ and Riley et al. ${ }^{16}$ However Nie $\mathrm{H}$ et $\mathrm{al}, 17$ found that females showed lower pain thresholds than males, but this difference was not significant and was likely due to small sample size (12 males, 12 females). The mechanisms underlying these differences remain unclear. One possible explanation suggests that males are more motivated to tolerate and suppress expressions of pain because of the masculine gender role, whereas the feminine gender role en-

Table 1. Age and anthropometric data of the study population (Unpaired student's t-test).

\begin{tabular}{lcc}
\hline Parameter & Male $(n=86)[$ Mean $\pm S D]$ & Female $(n=64)[$ Mean $\pm S D]$ \\
Age (in years) & $18.57 \pm 0.77$ & $18.37 \pm 0.81$ \\
Height (in meters) & $1.57 \pm 0.05$ & $1.58 \pm 0.06$ \\
Weight (in Kg) & $53.42 \pm 3.79$ & $52.65 \pm 4.80$ \\
Body Mass Index $\left(\mathrm{Kg} / \mathrm{m}^{2}\right)$ & $21.79 \pm 1.61$ & $21.14 \pm 1.49$
\end{tabular}

${ }^{*}$ p $<0.05$-statistically significant.

Table 2 shows gender differences in cardiovascular parameters in response to experimental pain. Mean pulse reactivity was higher in females ( 15.04 beats/minute) as compared to males (12.91 beats/minute), but this difference was not significant $(p=0.054)$. Mean systolic blood pressure reactivity was found to be higher in females $(9.26 \mathrm{mmHg}$ ) as compared to males (8.9 $\mathrm{mmHg})$, but this difference was not significant $(p=0.7)$. Also, mean diastolic blood pressure reactivity was found to be higher in females (6.3 $\mathrm{mmHg}$ ) as compared to males $(5.33 \mathrm{mmHg})$, but this difference was not significant $(p=0.26)$. Thus, there was no difference in cardiovascular response to experimental pain in both the genders with p>0.05 for all the parameters. courages pain expression and produces lower motivation to tolerate pain among females. ${ }^{18}$ Other mechanisms have been proposed to explain the differing response to experimental pain between the genders, including hormonal factors, differences in pain modulatory systems, and genetic factors. From a more psychosocial perspective, another potential explanation for the gender difference in pain responses involves social role expectancies. Different pain perception might account for gender difference in pulse reactivity. Hormonal influences may play a minor role. ${ }^{19}$

Sex hormones have effects throughout the nervous system and their plasma concentrations change on a regular basis

Table 2. Gender differences in cardiovascular parameters in response to experimental pain (Unpaired student's t-test).

\begin{tabular}{lcc}
\hline Parameter (Post test value minus Pre test value) & Male $(n=86)[$ Mean \pm SD] & Female $(n=64)[$ Mean \pm SD] \\
Pulse reactivity (beats/minute) & $12.91 \pm 8.69$ & $15.04 \pm 6.76$ \\
Systolic blood pressure reactivity $(\mathrm{mmHg})$ & $8.9 \pm 7.1$ & 9.054 \\
Diastolic blood pressure reactivity $(\mathrm{mmHg})$ & $5.33 \pm 5.81$ & $6.3 \pm \pm 6.26$
\end{tabular}

p<0.05-statistically significant.

Table 3 shows gender differences in pain sensitivity parameters in response to experimental pain. Males showed higher pain threshold (mean 22.57 seconds) as compared to females (mean 19.21 seconds) with $p<0.05$. Males showed higher pain tolerence (mean 77.68 seconds) as compared to females (mean 57.92 seconds) with $p<0.05$. Pain rating during experimental pain was found to be higher in females (mean 6.34) as compared to males (mean 5.45) with $p<0.05$. Thus, females were found to be more sensitive to pain than males.

Pulse reactivity showed a negative relationship with pain threshold and pain tolerance while a positive relationship with pain rating (Table 4), however no statistically significant relation was found between these measures ( $p>0.05$ for all correlations).

\section{Discussion}

Pain threshold and pain tolerance during experimental pain among both females and males. Also, hormone levels change throughout the menstrual cycle, during pregnancy, and after menopause in females. These differences may have major consequences for the pain perception. ${ }^{20}$ For example, a correlation between elevated estrogen levels and perception of experimental heat pain has been shown in some studies where elevated estrogen levels were associated with a lower heat tolerance threshold and heat pain. ${ }^{21}$ In females, the pain modulatory system shows menstrual variation with more effect in the ovulatory phase of cycle compared to the menstrual and luteal phase..$^{22,23}$ Whereas males, in spite of a significant decrease in their testosterone levels with advancing age, appear to be less vulnerable to changes in sex hormone levels during their entire lifespan. ${ }^{20}$

In this study, we found an inverse trend between pulse reactivity and pain sensitivity as indicated by pain threshold and 
Table 3. Gender differences in Pain sensitivity parameters in response to experimental pain.

\begin{tabular}{lcc}
\hline $\begin{array}{l}\text { Parameter } \\
\text { (Post test value minus Pre test value) }\end{array}$ & $\begin{array}{l}\text { Male }(n=86) \\
(\text { Mean } \pm \text { SD) }\end{array}$ & $\begin{array}{c}\text { Female }(n=64) \\
(\text { Mean } \pm \text { SD) }\end{array}$ \\
Pain threshold (seconds) & $22.57 \pm 6.81$ & $19.21 \pm 6.95$ \\
Pain tolerance (seconds) & $77.68 \pm 18.62$ & $57.92 \pm 14.47$ \\
Pain rating (o to 10) & $5.45 \pm 1.18$ & $6.34 \pm 1.16$
\end{tabular}

${ }^{*} p<0.05$-statistically significant, ${ }^{* *} p<0.01$-highly significant.

(NMDA and glycine) and estradiol produces significantly larger pain tolerance. This relation was also found by Myers et al., ${ }^{24}$ and Otto and Dougher in their studies. ${ }^{25}$

No difference was found in cardiovascular response to experimental pain between both the genders, a finding similar to Myers et al. ${ }^{24}$ There is no consensus regarding the reactivity-pain relationship, some studies found a direct relationship between systolic blood pressure reactivity and pain, ${ }^{26-29}$ and others found an inverse relationship. ${ }^{30,31}$ One possible explanation may be our measure of reactivity as several participants withdrew their hand from the cold water in very short time. An interplay of blood pressure levels, sympathetic nervous system and baroreceptor activity could explain the relationship between blood pressure and response to experimental pain. currents in females than males. ${ }^{41}$ The female central nervous system appears to be more sensitized to pain, as compared to male central nervous system, due to this estrogenic increase in excitability of spinal NMDA receptors. ${ }^{20}$

Many other factors that may be held responsible for gender differences in pain perception include race and ethnicity of person, endogenous and exogenous pain modulation, gonadal hormones, cognitive or affective parameters such as coping processes, and catastrophizing, the RIII reflex, pain related behaviors, social role expectancies, past painful experiences and genetic factors. ${ }^{20}$

Table 4. Correlation of Pulse reactivity with Pain Threshold, Pain tolerance and Pain rating (Pearson's correlation).

$\begin{array}{llcr}\text { Characteristic } & & \text { Pain Threshold } & \text { Pain tolerance } \\ \begin{array}{llll}\text { Male } & \text { Pulse reactivity } & r=-0.045, p=0.7539 & r=-0.044, p=0.7594 \\ \text { Female } & \text { Pulse reactivity } & r=-0.144, p=0.3173 & r=-0.0086, p=0.9522\end{array} \quad r=0.12, p=0.42 \quad \begin{array}{l}\text { Pain rating }\end{array}\end{array}$

${ }^{*} p<0.05$-statistically significant.

Pain causes sympathetic stimulation and elevates blood pressure levels which stimulates baroreceptors. These activated baroreceptors, in turn, initiate a signaling cascade that causes modulation of descending pain pathways to inhibit pain. The theory of hypertensive hypoalgesia suggests that elevated resting blood pressure levels will allow for a quicker stimulation of this baroreceptor mediated pain inhibitory activity with pain induced sympathetic arousal causing decreased pain perception in hypertensive individuals. ${ }^{32,33}$

Pain is a complex and subjective experience. There may be gender differences in the neural mechanisms that mediate pain perception. Size as well as morphology of various brain structures such as the corpus callosum, planum temporal, preoptic hypothalamic area, and percentage of grey matter show gender differences. ${ }^{34-37}$ Resting regional cerebral blood flow rate and the cerebral metabolic rate of glucose utilization may also differ in both gender. ${ }^{38-39}$ The human forebrain structures show gender related variation in their activation patterns in response to experimental noxious thermal stimulus e.g. females show significantly greater activation of the contralateral prefrontal cortex, contralateral insula and thalamus when compared to the males by positron emission tomography (PET) with intravenous injection of $\mathrm{H}_{2} 0 .{ }^{16,40} \mathrm{~N}$-methyl-D-aspartate (NMDA) receptor function in the dorsal horn of spinal cord also differs in males and females.20 Sustained activation of NMDA receptors on the second order neurons by glutamate, released from tonically active afferent nerve endings, increases the excitability of these neurons causing increased nociceptive responses. Stimulation of NMDA receptors by the application of agonists
Regarding the study limitations, more accurate and serial data could have been obtained if automated pulse and blood pressure (BP) recording had been done. Perceptions and reactivity to pain might be different in a real life situation compared to the laboratory set up. Moreover, we did not compared pain response between patients in a pathological state compared to those in a non-pathological state. Finally, we did not look into the hormonal and psycho-social aspects of the participants that could have been affected the pain response.

In conclusion our study suggests that gender of the subject plays a significant role in response to experimental pain with females being more sensitive to pain than males. There is a need for further research to investigate physiological, psychological, and socio-cultural influences on response to experimental pain. 


\section{References}

1. IASP Sub-committee on Taxonomy. Pain terms: a list with definitions and notes on usage. Pain 1980;8:249-52.

2. Hoffmann DE, Tarzian AJ. The girl who cried pain: a bias against women in the treatment of pain. J Law Med Ethics. 2001;29(1):13-27.

3. International Association for the Study of Pain. Fact Sheet: Children with Chronic Pain-Sex and Cender Differences. 2007.

4. Lowery D, Fillingim RB, Wright RA. Wright. Sex differences and incentive effects on perceptual and cardiovascular responses to cold pressor pain. Psychosom Med. 2003;65(2):284-91.

5. Wiesenfeld-Hallin Z. Sex differences in pain perception. Gend Med. 2005;2(3):137-45.

6. International Association for the Study of Pain. Fact Sheet: Differences in Pain Between Women and Men. 2007.

7. International Association for the Study of Pain. Fact Sheet: Epidemiology of Pain in Women. 2007.

8. Unruh AM. Gender variations in clinical pain experience. Pain. 1996;65(2 3):123-67.

9. Pud D, Golan Y, Pesta R. Hand dominancy-a feature affecting sensitivity to pain. Neurosci Lett. 2009;467(3):237-40.

10. Joseph L. Riley, Michael E. Robinson, Emily A. Wise, Donald Price. A meta-analytic review of pain perception across the menstrual cycle. Pain. 1999;81(3):225-235.

11. Schulz KF, Altman DG, Moher D, for the CONSORT Group. CONSORT 2010 Statement: updated guidelines for reporting parallel group randomised trials. Ann Int Med. 2010;152.

12. Garrow JS, Webster J. Quetelet's index (W/H2) as a measure of fatness. Int J Obes. 1985;9(2):147-53.

13. Mitchell LA, MacDonald RA, Brodie EE: Temperature and the cold pressor test. J Pain. 2004;5(4):233-7.

14. Joshi M. Evaluation of pain. Indian J. Anaesth. 2006;50(5):335-9.

15. Fillingim RB, Maixner W. Gender differences in the responses to noxious stimuli. Pain Forum. 1995;4(4):209-1.

16. Riley JL 3rd, Robinson ME, Wise EA, Myers CD, Fillingim RB. Sex differences in the perception of noxious experimental stimuli: A meta-analysis. Pain. 1998;74(2-3):181-7.

17. Nie H, Arendt-Nielsen L, Andersen H, Graven-Nielsen T. Temporal summation of pain evoked by mechanical stimulation in deep and superficial tissue. J Pain. 2005;6(6):348-5.

18. Myers CD, Robinson ME, Riley JL 3rd, Sheffield D. Sex, gender, and blood pressure: contributions to experimental pain report. Psychosom Med. 2001;63(4):545-50.

19. Berkley KJ. Sex differences in pain. Behav Brain Sci. 1997;20(3):371-80. 20. Fillingim RB, King CD, Ribeiro-Dasilva MC, Rahim-Williams B, Riley JL 3 rd. Sex, Gender, and pain: A review of recent clinical and experimental findings. J Pain. 2009;10(5):447-85.

21. Fillingim RB et al. Ischemic but not thermal pain sensitivity varies across the menstrual cycle. Psychosom Med. 1997;59:512-520.

22. Yannick Tousignant-Laflamme, Serge Marchand. Excitatory and inhibitory pain mechanisms during the menstrual cycle in healthy women. Pain. 2009; 146:47-55

23. M. Teepker, M. Peters, H. Vedder, K. Schepelmann, S. Lautenbacher Mens- trual Variation in Experimental Pain: Correlation with Gonadal Hormones. Neuropsychobiology. 2010;61:131-40.

24. Myers CD, Robinson ME, Riley JL 3rd, Sheffield D. Sex, gender, and blood pressure: contributions to experimental pain report. Psychosom Med. 2001;63(4):545-50.

25. Otto MW, Dougher MJ. Sex differences and personality factors in responsivity to pain. Percept Mot Skills. 1985;61(2):383-90.

26. Schobel HP, Ringkamp M, Behrmann A, Forster C, Schmieder RE, Handwerker H0. Hemodynamic and sympathetic responses to painful stimuli in normotensive and borderline hypertensive subjects. Pain. 1966;66(2-3):117-24. 27. Peckerman A, Saab PG, McCabe PM, Skyler JS, Winters RW, Llabre MM et al. Blood pressure reactivity and perception of pain during the forehead cold pressor test. Psychophysiology. 1991;28(5):485-95.

28. Bruehl S, Carlson CR, McCubbin JA. The relationship between pain sensitivity and blood pressure in normotensives. Pain. 1992;48(3):463-7.

29. Maixner W, Humphrey C. Gender differences in pain and cardiovascular responses to forearm ischemia. Clin J Pain. 1993;9(1):16-25.

30. France CR, Stewart KM. Parental history of hypertension and enhanced cardiovascular reactivity are associated with decreased pain ratings. Psychophysiology. 1995;32(6):571-8.

31. Rosa C, Chione S, Mezzasalma L, Pellegrini M, Basile Fasolo C, Giaconi S, et al. Relationship between pain sensitivity, cardiovascular reactivity to cold pressor test, and indexes of activity of the adrenergic and opioid system. Clin Exp Hypertens A. 1988;10 Suppl 1:383-90.

32. Bruehl S, Chung OY. Interactions between the cardiovascular and pain regulatory systems: an updated review of mechanisms and possible alterations in chronic pain. Neurosci Biobehav Rev. 2004;28:395-414.

33. Bruehl $S$ et al. Hypoalgesia associated with elevated resting blood pressure: evidence for endogenous opioid involvement. J Behav Med. 2010;33:168176.

34. Swaab DF, Fliers E. A sexually dimorphic nucleus in the human brain. Science. 1985;228(4703):1112-5.

35. Allen LS, Gorski RA. Sex difference in the bed nucleus of the stria termi nalis of the human brain J Comp Neurol. 1990;302(4):697-706.

36. Allen LS, Gorski RA. Sexual dimorphism of the anterior commissure and massa intermedia of the human brain. J Comp Neurol. 1991;312(1):97-104. 37. Kulynych JJ, Vladar K, Jones DW, Weinberger DR. Gender differences in the normal lateralization of the supratemporal cortex: MRI surface-rendering morphology of Heschl's gyrus and planum temporale. Cereb Cortex. 1994;4(2):107-18

38. Gur RC, Mozley LH, Mozley PD, Resnick SM, Karp JS, Alavi A, et al. Sex differences in regional cerebral glucose metabolism during a resting state. Science. 1995;267(5197):528-31.

39. Andreason PJ, Zametkin AJ, Gus AC, Baldwin P, Cohen RM. Gender-related differences in regional cerebral glucose metabolism in normal volunteers. Psychiatry Res. 1994;51(2):175-83.

40. Gender differences in pain perception and patterns of cerebral activation during noxious heat stimulus in humans. Pain. 1998;76(1-2):223-9.

41. McRoberts JA, Li J, Ennes HS, Mayer EA. Sex-dependent differences in the activity and modulation of $\mathrm{N}$-methyl-d-aspartic acid receptors in rat dorsal root ganglia neurons. Neuroscience. 2007;21(148):1015-20.

\section{Acknowledgments}

None.

\section{Conflict of Interest Statement a Funding}

The authors have no funding, financial relationships or conflicts of interest to disclose.

\section{Cite as:}

Akhani PN, Mendpara SJ, Palan BM, Harsoda JM. Gender Differences in Response to Experimental Pain Among Medical Students from a Western State of India. Int J Med Students. 2014;2(1):13-7. 